\title{
Sensor Lag Correction for Mobile Urban Microclimate Measurements
}

\author{
Kathrin Häb ${ }^{1}$ \\ Computer Graphics and HCI Group, University of Kaiserslautern, Germany \\ Benjamin L. Ruddell \\ Fulton Schools of Engineering, Arizona State University, USA \\ Ariane Middel \\ School of Geographical Sciences \& Urban Planning, Arizona State University, USA
}

\begin{abstract}
Some uncertainty in mobile microclimate observations stems from sensor lags. This is especially critical in mobile transect campaigns conducted in urban areas, where observations have to be related to the quickly varying complex surroundings of the sensor, which becomes difficult if the sensor has a high time constant relative to environmental scale and sensor velocity. We present an optimized method for sensor lag correction using a transfer function, based on the optimization of three correction parameters: moving average window size, transfer function setup, and linear time shift. We evaluate the method by comparing the corrected temperatures measured with a "slow" Resistance Temperature Detectors (RTD) to a ground truth provided by synchronous measurements with thermocouples that have a time constant of less than one second. Theoretical assumptions about the correction procedure design are substantiated by the optimization procedure, which yields consistent results for mobile transect data sets recorded at different times of day and in different seasons.
\end{abstract}

Keywords: Urban Microclimate, Mobile Measurements, Sensor lag correction

\footnotetext{
${ }^{1}$ Corresponding author P.O. Box 3049, 67653 Kaiserslautern, Germany kathrin.haeb@cs.uni-kl.de

Preprint submitted to Urban Climate
}

August 31, 2015

(C) 2015. This manuscript version is made available under the Elsevier user license http://www.elsevier.com/open-access/userlicense/1.0/ 


\section{Introduction}

Mobile transect measurements are used in urban climate studies to retrieve information about canopy-layer urban heat island characteristics [1, 2, 3, 4, park cool island intensities 5, to more generally investigate the effect of land 5 use configurations on urban microclimate [6, 7, and to assess thermal comfort 8. In all of these applications, the sensors need to accurately sample the microclimate in a dynamically changing physical environment. The combined effects of sensor inertia, air speed, sampling frequency, and platform velocity determine the spatial resolution of the transect data $[9]$.

Sensor inertia is dependent on the time constant $\tau_{63}$, which is defined as the time a sensor needs to adapt to $63 \%$ of an impulse change [10, 9. For air temperature sensors, this impulse is a change in the ambient temperature, which can occur frequently during a mobile transect run. With larger time constants, the temperature curve recorded by a sensor is smoothed because local minima and maxima cannot be resolved [9, 11]. Mayer et al. [11] and Foken [10] refer to this error as the dynamical error, causing an attenuation of the measured air temperature amplitudes [11]. Mayer et al. [11] also state that lag-times can complement this error. As the dynamical error, they are caused by the inertia of the entire measurement system (sensor and housing) and provoke temperature differences to be registered later than they actually appear [11.

Although sensor lag effects also impact stationary measurement systems 12 13, they are generally an important factor when a sensor is moved through space [11. Studies on sensor inertia have thus been carried out in the context of radiosonde or airborne temperature measurements, in which the sensor moves at very high air speed and velocity [14, 15, 16, 17, 18, 19, 20. Frequently, it is assumed that the sampled temperature is a convolution between the true temperature and some transfer function, e.g. the time-derivative of the impulse response function using the time constants of the sensor and its housing [14, 15, 18. or solely the time constant of the sensor [9. The transfer function can then 
be interpreted as a filter for the true temperature, i.e. the convolution of the true temperature and the transfer function yields the measured temperature. Thus, deconvolution of the measured temperature results in the true temperature [14, 15, 17.

Studies on sensor lag correction for ground-based, micrometeorological mo35 bile measurements and the verification of the approaches from radiosonde or aircraft measurements for this setting are rare [11. Mayer et al. [11] successfully demonstrate the applicability of the deconvolution approaches by Inverarity 15 and McCarthy [14] to vertical measurements conducted with an elevator tower. They found good agreement between the corrected elevator measurements and the stationary measurements conducted at different heights on a nearby mast. In addition, they developed a simpler correction scheme for two time constants that relies on the subsequent application of the weighted sensor response function for the time constants of the probe and its housing, achieving similar good results for their simpler correction procedure [11].

Hübner et al. 21] and Achberger and Bärring [9] investigate correction procedures for horizontally moving sensors during mobile transects in a micrometeorological context. Hübner et al. 21] installed a horizontal mobile measurement system based on a garden railway perpendicular to a forest edge and examine how the correction procedure using a linear adjustment of the impulse response function can reproduce the step-change in air temperature at the transition between forest and clearing. Achberger and Bärring [9] use a correction filter based on the combination of a low-pass-filter and the time-derivative of the impulse response function, similar to McCarthy [14] and Inverarity [15]. To verify their approach, they compare the corrected air temperature to the values recorded by a nearby stationary sonic anemometer. They are able to bring the power spectra of the two air temperature time series into accordance, although the different spatial positions of the two sensors pose restrictions on the direct comparability of the two data sets.

In this study, we apply the approach for sensor lag correction reported by ${ }_{60}$ Achberger and Bärring [9] to an urban microclimate setting, using moving av- 
erage as a low-pass filter, and adding a linear shift of the corrected time series. The correction procedure is carried out for air temperature, which is one of the most important variables for urban heat island 22 and micrometeorology studies. Air temperatures at two different heights were measured using Resistance Temperature Detectors (RTD) and Fine-Wire Thermocouples (FWT) simultaneously while moving a a sensor platform through a residential area in the Phoenix Metropolitan area. The mobile measurements were conducted as part of a larger project, following the goal to observe space and time variations in intra-canopy microenvironmental conditions as a basis for empirical and process-based model development. In this paper, we describe how measurements with relatively slow sensors (in our case RTDs) can be corrected to estimate high-resolution observations (conducted with FWTs) in an urban environment.

\section{Materials and Methods}

75 2.1. Study site

The data set used to conduct this study was recorded at Power Ranch, a master-planned community in Gilbert, Arizona, USA (33.27 N, -111.69 W, 406 m a.s.l.). According to the U.S. Census Bureau Population Estimate for 2014, Gilbert has 239, 277 inhabitants [23] and a land area of $176.02 \mathrm{~km}^{2}$ [24]. The city

${ }_{80}$ is located in the southeastern part of the Phoenix Metropolitan Area (Fig. 1), situated in the northeastern Sonoran Desert. The climate in Phoenix is hot and semiarid, with mean daily minimum temperatures ranging from $7.1^{\circ} \mathrm{C}$ in December to $28.1^{\circ} \mathrm{C}$ in July, and mean daily maximum temperatures ranging from $19.6^{\circ} \mathrm{C}$ in December to $41.0^{\circ} \mathrm{C}$ in July. The average annual precipitation 85 is $207.7 \mathrm{~mm}[25]$.

As summarized by Chow et al. [26], the Phoenix Metropolitan Area comprises several urban climate features, which have been investigated in various studies during the last decades. One of these features is a pronounced Urban Heat Island (UHI) effect, which is most intensive at night and during clear con- 
ditions [26, 27, 4]. The UHI intensity in the Phoenix Metropolitan Area is not negatively affected by wind speeds up to a certain threshold [4, 27, which might be due to the katabatic wind flow induced by the mountains located to the east and south side of the Phoenix Metropolitan Area [4. The katabatic winds cause a transition of wind directions at night, bringing cooler air from the mountains down to the valley and thereby intensifying the urban-rural temperature differences. They can thus be seen as a distinct feature of the climate in the Phoenix Metropolitan Area [26, 28, 4]. In addition to that, the dry air in the desert city causes a high evaporation potential, leading to lower air temperatures in and around vegetated areas [26, 5, 29, 30].

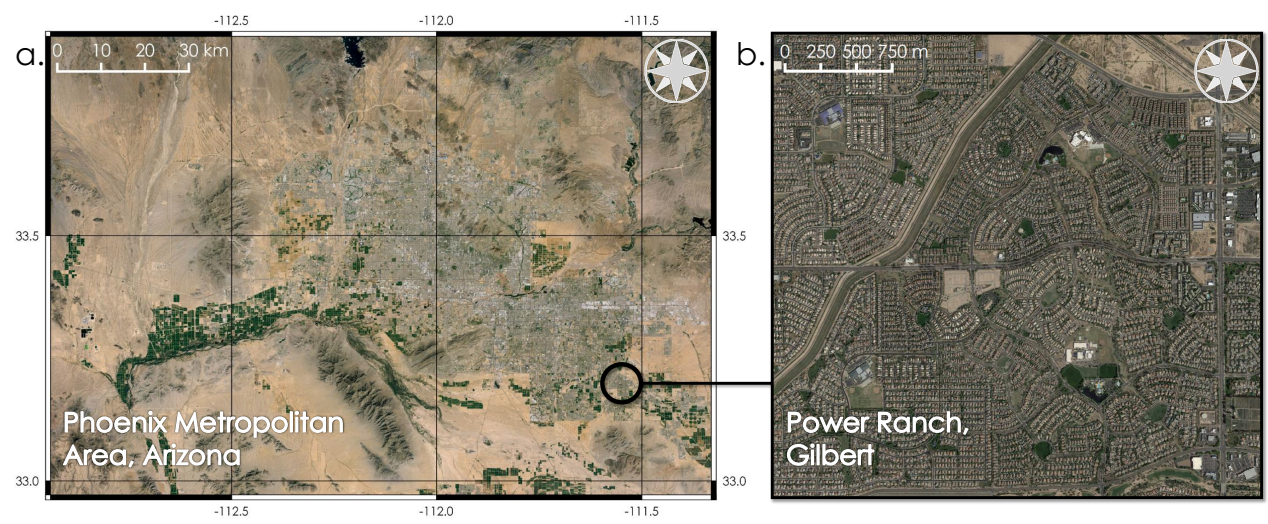

Figure 1: (a) Location of the study area within the larger context of the Phoenix Metropolitan Area, Arizona, USA. (b) Satellite image of the study area: Power Ranch, Gilbert (Images: Google 2015).

Power Ranch is a diverse residential neighborhood featuring excellent examples of the typical canopy structures, land covers, and landscape architectures found in a Western U.S. city. It mainly consists of low-rise residential buildings arranged in single-family home neighborhoods, lined up along asphalt roads and concrete sidewalks. All homes are surrounded by yards, which frequently feature a swimming pool and have landscaping types ranging from desert-like xeriscaping to irrigation-intensive mesic landscaping. The space between neighborhoods is occupied by parks, a large portion of which is covered by grass. An 
artificial lake is located in the center and in the northern part of Power Ranch, respectively. Mobile transects traverse these microenvironments during many times of day and in different seasons, while the routes were chosen to cover the full diversity of landscaping types available in Power Ranch (Fig. 2).

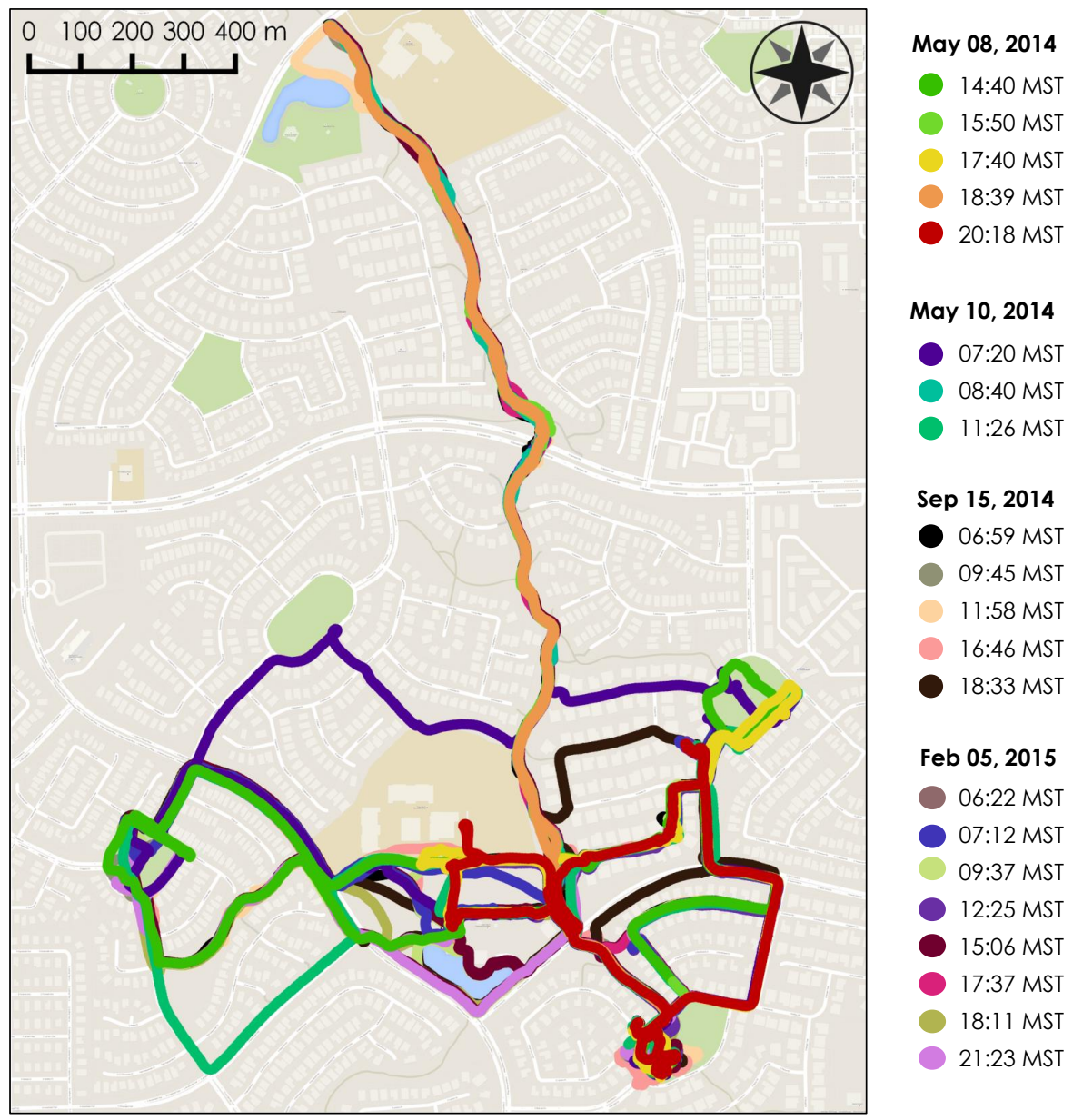

Figure 2: Transect runs in Power Ranch.

\subsection{Instrumentation}

Four air temperature sensors were used in this study. Two of these sensors are Resistance Temperature Detectors (RTD) used in the Rotronic HC2S3 combined temperature and relative humidity probe. The RTDs are platinum type 
and have a resistance of $100 \Omega(\mathrm{Pt100}$ RTD). Their rated measurement range lies between $-40^{\circ} \mathrm{C}$ and $+60^{\circ} \mathrm{C}$, while their precision is $\pm 0.1^{\circ} \mathrm{C}$ at $23^{\circ} \mathrm{C}$ 31.

The other two sensors are Campbell Scientific FW3 thermocouples, which are Fine-Wire Thermocouples (FWT) of Type E (Chromel-Constantan) with a diameter of $0.0762 \mathrm{~mm}$ [32]. In accordance with the thermistor located onboard the CR1000 data logger, they have a precision of $\pm 0.1^{\circ} \mathrm{C}$ in a range between $0^{\circ} \mathrm{C}$ and $40^{\circ} \mathrm{C} 33$. A typical time constant for a thermocouple of this diameter is $0.6 s$ in still air (Table 2 in [34] ${ }^{2}$.

The sensors were calibrated by the manufacturer. To confirm that sensors at equal heights measure the same air temperature, we recorded a reference time series over $4.5 \mathrm{~h}$ at night with the platform remaining at the same place. The comparison between the average air temperature sampled by the FWT and the RTD mounted at $2 \mathrm{~m}$ showed a difference of $0.040^{\circ} \mathrm{C}$, while the air temperature sampled with the FWT and the RTD mounted at $1 m$ deviated by $0.044{ }^{\circ} \mathrm{C}$. This difference is negligible since they are not within sensor accuracy.

The sensors are mounted on a mast attached to the front of a golf cart (Fig. 3). One pair of sensors consisting of a HC2S3 Pt100 RTD and a thermocouple is located at each of the two measurement heights $(1 \mathrm{~m}$ and $2 \mathrm{~m}$ ) to make the measurements of the two sensors comparable. The RTDs are housed in naturally ventilated M.R. Young 10-plate radiation shields. The sensors in the lower level are located at a distance of $0.5 m$ (HC2S3 RTD) and $0.7 m$ (FWT) to the front part of the vehicle, which we assume to be sufficient in order to minimize the cart's impact on the observations. Due to natural ventilation, the air in the volume between the cart's hood and the sensor is exchanged quickly, which prevents the sensors at $1 \mathrm{~m}$ height to capture the influence of the vehicle's surface. Meteorological data were recorded at $1 \mathrm{~Hz}$ frequency and logged with a Campbell Scientific CR1000 data logger mounted to the back of the golf

\footnotetext{
${ }^{2}$ The response times for a fine gauge thermocouple of Type J (Iron-Constantan) are listed in this table. However, Campbell Scientific Customer Support referred to this table for a time constant estimate for the FW3 Type E thermocouple.
} 
cart. In addition to the meteorological data, the platform velocity vector and the position of the golf-cart are tracked using a GPS device.

\subsection{The time constant of the HC2S3 Pt100 RTD}

To determine the time constant for the HC2S3 Pt100 RTD, we followed the procedure described by Mayer et al. [11] and Blennow et al. [35. The ambient air temperature was measured using a reference sensor, while the target sensor was heated up by applying an external heat source. After the heat source was removed, the sensor was placed into a naturally ventilated 10-plate radiation shield to determine the time constant for the entire measurement system. Target sensor air temperatures were recorded at a frequency of $1 \mathrm{~Hz}$, until they reached the value measured by the reference sensor. This procedure was carried out while exposing the RTD and the radiation shield to still air, as well as to wind speeds ranging from approx. $3.2 \mathrm{~m} / \mathrm{s}$ up to approx. $7 \mathrm{~m} / \mathrm{s}$. During the experiments, the specific humidity of the surrounding air remained nearly constant, averaging at $8.39 \mathrm{~g} / \mathrm{kg}$. This value is approximately in the center of the humidity levels that were predominant during the May transect runs (on average $4.53 \mathrm{~g} / \mathrm{kg}$ ), during the September transect runs (on average $11.9 \mathrm{~g} / \mathrm{kg}$ ), and during the February transect runs (on average $6.64 \mathrm{~g} / \mathrm{kg}$ ). It can thus be assumed that the time constant is representative for the data sets under consideration in this study.

In accordance to Mayer et al. [11, we computed the time constant from the experimental data by first determining the normalized response using the following expression:

$$
T_{\text {norm }}(t)=\frac{\left|T_{\text {target }}(t)-T_{\text {target }}(0)\right|}{T_{\text {target }}(0)-T_{\text {ref }}}
$$

where $t$ is the time, $T_{\text {target }}(t)$ is the time series sampled by the heated up sensor, $T_{\text {target }}(0)$ is the maximum temperature of the target sensor at the beginning of each experiment, and $T_{r e f}$ is the reference temperature, measured by the reference sensor and averaged over the duration of each experiment. Equa170 tion 1 yields values around 0 for $T_{\text {norm }}(0)$, while approching 1 for $T_{\text {norm }}\left(t_{\max }\right)$. 
To finally determine $\tau_{63}$, we fitted the exponential impulse response function to the normalized response curve [11, 35]. The impulse response function is given by $[11,10,20$.

$$
f(t)=\left(1-e^{\frac{-t}{\tau}}\right)
$$

Results imply that the time constant for the entire measurement system

175

$\tau_{63, \text { mov }}=46.21 \mathrm{~s}$ with a standard deviation of $3.7 \mathrm{~s}$. For still air, the time constant is $\tau_{63, \text { still }}=172.66 \mathrm{~s}$ with a standard deviation of $0.08 \mathrm{~s}$. The HC2S3 Pt100 RTD is a sensor with a relatively slow response time, which, without correction, is not necessarily suited for mobile measurements in complex terrain.
However, since this sensor is combined with a hygrometer within the Rotronic HC2S3 combined temperature and humidity probe, it was still applied in this study, allowing us to evaluate a strategy for sensor lag correction. It should also be noted that, oftentimes, faster sensors are not available, which is the case for humidity observations.

\subsection{Mobile measurements and data preprocessing}

The data were recorded during 21 transect runs (Fig. 2) conducted on four different days and three different times of year (May, September, and February). Each transect covers areas with buildings and open spaces, thus representing a variety of land covers. The physical scale of expected microclimate variation ranged from approx. $10 \mathrm{~m}$ (moving the golf cart over an intersection while driving between two arrays of evenly spaced houses before and after this intersection) to approx. $400 \mathrm{~m}$ (crossing the park in the center of the study area in east-west direction; see also Figure 4). Microclimate heterogeneity is maximized by driving the mobile platform through intermittent shade of trees located next to the route and by periodically stopping the platform in selected microenvironments that consist of various combinations of ground cover and shade types. This routine was followed during 17 of the 21 transect runs, with the cart on 


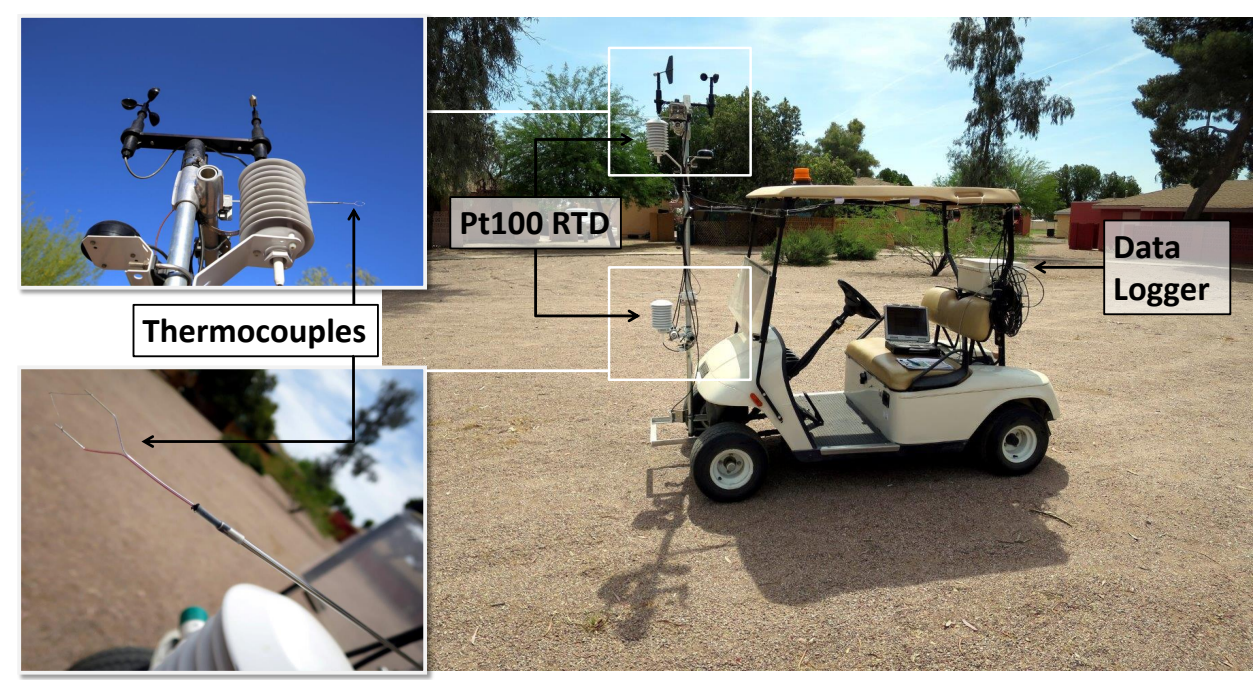

Figure 3: Measurement platform and thermometer setup.

average being stopped for $65.5 \%$ of the entire transect duration, with stop intervals ranging from $1 s$ to $632.4118 s$ on average, but reaching a maximum of $4348 s$ for the run conducted on February 5, 2015, 15:06 MST. While not stopping, the platform was moved at an average speed of $3.51 \mathrm{~m} / \mathrm{s}$. The remaining three runs are "activity runs", i.e. the cart is not stopped as often as during the tree runs (on average only $18.3 \%$ of the entire transect duration, for a maximum of $39 \mathrm{~s}$ ). For the activity runs, the platform is moved at an average speed of $4.88 \mathrm{~m} / \mathrm{s}$ when not stopping. Using mobile transect measurements including full stops is advantageous for the development of a sensor lag correction scheme suited for a realistic platform movement. In many cases, vehicles must stop, and a correction method must handle those stops properly.

The measurements were carried out between 14:40 MST and 21:22 MST on May 08, 2014 (five runs), between 07:20 MST and 12:57 MST on May 10, 2014 (three runs), between 06:59 MST and 19:36 MST on September 15, 2014 (five runs), and between 06:22 MST and 22:14 MST on February 05 (eight runs). The duration of the transect runs ranged between 16 and 144.5 minutes, which is long enough for the diurnal cycle to affect measurements. Weather conditions 
a.

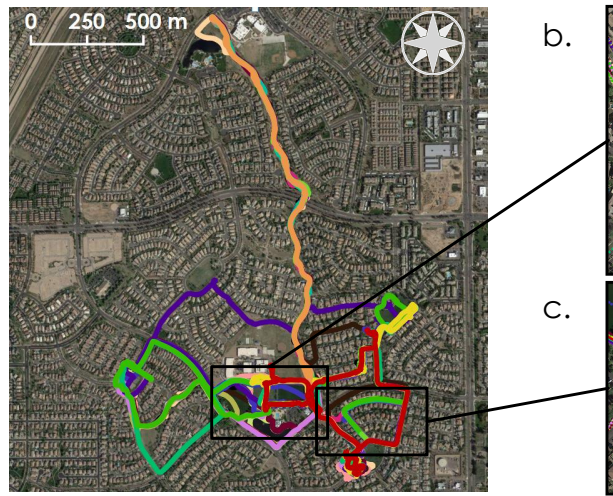

.

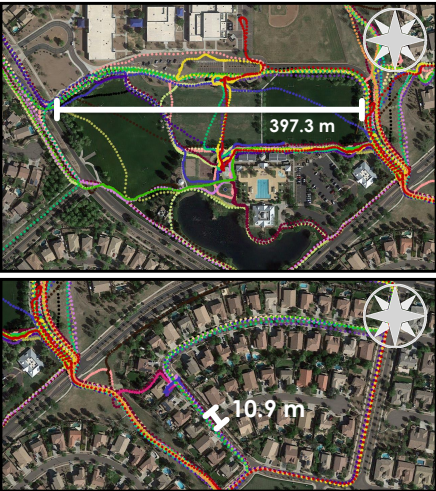

Figure 4: Estimates of the largest and smallest microclimate scale in the study area. a. Area overview. The colors correspond to different transect runs, as indicated in Figure 2 b. Hypothesis of the largest physical microclimate scale. c. Hypothesis of the smallest physical microclimate scale (only parts of the sidewalk are counted). Background image: Google.

during the runs are listed in Table 1. Mostly calm and clear days were selected for the measurements, since these conditions favor strong gradients between different environments [36, 37.

During all transect runs, the recordings from the surrounding weather stations indicated a change in the reference temperature. To account for these changes, we time-detrended the air temperature for each run and each of the two RTD and two FWT time series independently, using a linear best fit timetrend between time and air temperatures recorded by the platform to adjust all samples to the baseline observed at the beginning of each transect.

\subsection{The spatial resolution of mobile measurements}

The estimated physical microclimate scale along the transect route is approximately $10 \mathrm{~m}$ at its minimum, based on the scale of variation of the urban canopy structure and land cover. Therefore, the sampling frequency of the measurement system needs to be faster than $0.5 \mathrm{~Hz}$ for an average platform speed of $5 \mathrm{~m} / \mathrm{s}$ to resolve the meteorological impact of these microenvironments. Although our data are logged with a frequency of $1 \mathrm{~Hz}$ and the FWT sensors have a time constant below one second, the spatial resolution of the RTD is notably 


\begin{tabular}{|l|l|l|l|l|}
\hline Date and time & $\begin{array}{l}\text { Average air } \\
\text { temperature } \\
\left.\text { [ }{ }^{\circ} \mathrm{C}\right]\end{array}$ & $\begin{array}{l}\text { Average wind } \\
\text { speed }[\mathrm{m} / \mathrm{s}]\end{array}$ & $\begin{array}{l}\text { Average } \\
\text { relative } \\
\text { humidity [\%] }\end{array}$ & Cloud cover \\
\hline $\begin{array}{l}\text { May 08, 2014 } \\
\text { 14:40 MST -21:22 MST }\end{array}$ & 26.40 & 1.06 & 18.17 & $\begin{array}{l}\text { thinly scattered to } \\
\text { scattered in early } \\
\text { afternoon }\end{array}$ \\
\hline $\begin{array}{l}\text { May 10, 2014 } \\
\text { 07:20 MST - 12:57 MST }\end{array}$ & 27.21 & 1.38 & 19.90 & clear \\
\hline $\begin{array}{l}\text { September 15, 2014 } \\
\text { 06:59 MST - 19:36 MST }\end{array}$ & 36.02 & 1.31 & 29.54 & $\begin{array}{l}\text { thinly scattered to } \\
\text { scattered starting } \\
\text { from noon }\end{array}$ \\
\hline $\begin{array}{l}\text { February 05, 2015 } \\
\text { 06:22 MST - 22:14 MST }\end{array}$ & 19.58 & 0.50 & 50.30 & $\begin{array}{l}\text { thinly scattered } \\
\text { until late } \\
\text { afternoon, then } \\
\text { clear }\end{array}$ \\
\hline
\end{tabular}

Table 1: Reference weather during the mobile measurements, averaged over the time span in which all measurements of a day took place (reference meteorology from MesoWest 2014 [38]: Cloud cover from KIWA Phoenix-Mesa Gateway, temperature and wind data are averaged from four nearby stations surrounding the study site, i.e. AU340 Gilbert, D2495 Gilbert, AT202 Gilbert, and SRP31 Rittenhouse).

restricted by its time constant, which is $46.21 s$ at wind speeds approaching the platform speed. In simple mathematical terms, this relationship can be written as

$$
r^{*}=v \tau
$$

where $r^{*}$ is the resolvable microclimate scale $[m], v$ the platform speed $\left[m s^{-1}\right]$, and $\tau$ the time constant of the sensor $[s]$. The time constant is dependent on the ventilation of the sensor [39, which we, in the following, assume to be equal to the average platform speed of $3.77 \mathrm{~ms}^{-1}$. We neglect the ventilation of the sensor due to ambient wind speeds, since surrounding weather stations indicate that wind speeds are slower than the average platform velocity (Table 1). 


\subsection{Strategies to correct for sensor inertia}

\subsubsection{Retrieving the true air temperature spectrum from measurements}

The relationship between the true temperature and the temperature mea-

sured by a sensor can be described by the convolution integral

$$
T_{m}(t)=\int_{-\infty}^{t} T_{a}\left(t^{\prime}\right) h\left(t^{\prime}\right) d t^{\prime}
$$

where $T_{m}$ is the measured temperature and $T_{a}$ the true temperature [9, 11, 14, 15. $h$ is a transfer function that expresses the sensor response to a unit impulse change and can be described using the time-derivative of the impulse response function

$$
h(t)=\frac{1}{\tau} e^{\frac{-t}{\tau}}
$$

where $\mathrm{t}$ is the time in seconds 9 ([15] and [14) use the same equation with two time constants). Using the relationship described in Equation 4 , the true temperature can be obtained by de-convoluting the measured temperature [9, 11, 14, 15. McCarthy [14, Inverarity [15] and Mayer et al. [11] describe sensor lag correction procedures for measurement systems with two time constants. time lags in addition to those of the sensor itself. In these cases, the transfer function consists of a linear combination of twice the expression in Equation 5 . one of which uses the time constant of the sensor, while the other one uses the time constant of the housing [11, 14, 15].

In this study, we adapt the approach described by Achberger and Bärring [9, who model the response of the sensor to an impulse-like temperature change of $1^{\circ} \mathrm{C}$ using Equation 5 . Since we determined the time constant of the entire measurement system, i.e. for the combined effects of air temperature sensor and radiation shield, this approach is also appropriate for our data set. Achberger 
series and Equation 5 to ease the convolution, so that Equation 3 becomes

$$
G(f)=F(f) H(f)
$$

where $G(f)$ is the Fourier transform of the measured air temperature time series, $F(f)$ the Fourier transform of the true temperature, and $H(f)$ the Fourier transform of Equation 5. The true temperature spectrum can now simply be obtained by solving Equation 5 for $F(f)$ [9].

The choice for $\tau$ in Equation 5 is one of the parameters, which we yield to optimize in our approach. The most natural choice for a moving sensor platform would be $\tau_{63, m o v}$, although possible factors increasing the time constant, such as reduced ventilation while the platform stops, could motivate the selection of a larger value.

\subsubsection{Low-pass filter and linear shift}

The deconvolution procedure as described above also amplifies noise [9, 15]. Thus, it is important to use a low-pass filter to avoid this unwanted amplification. Achberger and Bärring [9] choose a cut-off frequency according to a change of slope in the power spectrum of the measured air temperature, since higher frequencies can be interpreted as noise (9] after Kaimal and Finnigan 1994). However, the authors do not specify which particular low-pass filter they use. Inverarity (2000) [15] apply a single-pole recursive filter to their data, which is similar to a -3dB cut-off. Miloshevich et al. [20] develop a a derivative-based smoothing algorithm, which minimizes the change of curvature in the given time series before they apply their correction procedure to humidity measurements sampled using a radiosonde.

Similarly to McCarthy [14, but in another context, we want to leave major trends in the data as they are, while filtering out short-term temperature fluctuations. Thus, we follow this approach and smooth the RTD time series by utilizing a simple two-sided unweighted moving average as low-pass filter as 
given by

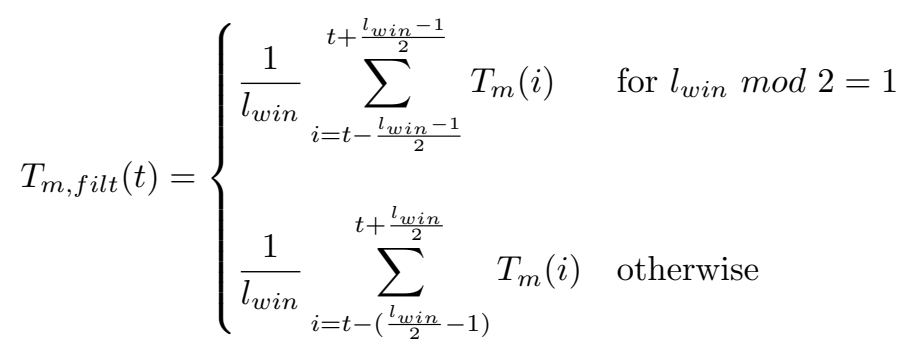

and as implemented in the R "zoo" package (40, function "rollmean"; note that even numbers are also possible as input). In signal processing terms, the moving average filter does not cut-off higher frequencies, but continuously attenuates their power up to the Nyquist frequency (Fig. 5p).

The size of the moving average window is another parameter that we aim to optimize in this study. This parameter is dependent on the amount of noise that is apparent in the data, which is in turn dependent on the sensor, the platform speed, and the physical microclimate variation experienced by the sensor. During our measurements, the platform moved at a maximal average speed of $5.23 \mathrm{~m} / \mathrm{s}$ (averaged over all speeds of a transect run, excluding the instances when the cart stopped) over potentially climatologically relevant patches with an extent of minimally $10 \mathrm{~m}$. Following Equation 3, there cannot be any physically motivated variation occurring at a time interval that is smaller than approx. $2 s$, which we thus chose as a lower bound for the moving average window size. The upper bound can be derived in analogy to the lower bound: the sensor is moved with a minimal average speed of $2.41 \mathrm{~m} / \mathrm{s}$ (averaged over all speeds of a transect run, excluding the instances when the cart stopped) over patches with an extent of maximal $400 \mathrm{~m}$, leading to an upper bound of approx. $166 \mathrm{~s}$. An intuitive and theoretically natural choice for the moving average window size would be dependent on $\tau_{63, \text { mov }}$ because this value takes the sensor's spatial resolution into account.

For the FWT sensor, we smoothed the data using a moving average window size of $2 s$ because of its time constant of $\tau_{63}=0.6 s\left(\tau_{95}=3 \cdot \tau_{63}=1.8 s\right)$. Following Equation 3, the low $\tau_{63}$ implies that the sensor is theoretically able 
to resolve spatial air temperature variations of all patches with a spatial extent larger than $3.14 m$ (9.41 $m$ to resolve $95 \%$ of the resulting impulse change), while moving at a speed of $5.23 \mathrm{~m} / \mathrm{s}$. Since the smallest patch has an extent of $10 \mathrm{~m}$, large FWT-measured air temperature variation occurring within a time interval of less than $2 s$ is improbable.

The application of the deconvolution described in Section 2.6.1 on the filtered RTD temperature leads to results where major features of the variability of the "ground-truth" FWT sensor can be reproduced. However, in most cases, there 325 is a linear shift between the corrected RTD and the raw (but time-detrended) FWT time series. This linear shift causes the local maxima and minima in the corrected RTD time series to appear later than in the FWT series (lagtime [11) and is caused by the response time of the entire measurement system [11, 21]. Choosing a multiple of $\tau_{63, \text { mov }}$ in Equation 5 can attenuate this effect, 330 but on the other hand, it can also intensify the amplitude between local minima and maxima in the time series, causing larger-than-necessary deviations from the "ground-truth". Therefore, the amount of linear shift to balance out an optimal choice for $\tau$ in Eq. 5 is the third parameter that we attempt to optimize in this study.

2.6.3. Optimizing the parameter choice

Three parameters were optimized in this study: the choice for the moving average window size, the choice for $\tau$ in Equation 5, and the choice for the amount of linear shift. For each of these parameters, we iterated through all possible combinations of the elements included in the following sets (all values are based on $\left.\tau_{63, m o v}\right)$ :

- Moving average window size: $\{2,11,23,34,46,57,69,92,115,138,161,166\}$

- $\tau$ in Equation $5\left\{0.5 \tau_{63}, \tau_{63}, \tau_{86}, \tau_{95}, \tau_{99}\right\}$

- Amount of linear shift: $\left\{n \in \mathbb{N}^{0} \mid n \leq 46\right\}$

We applied each of these parameter combinations to correct the RTD measurements according to the procedure described in the previous Sections. For 

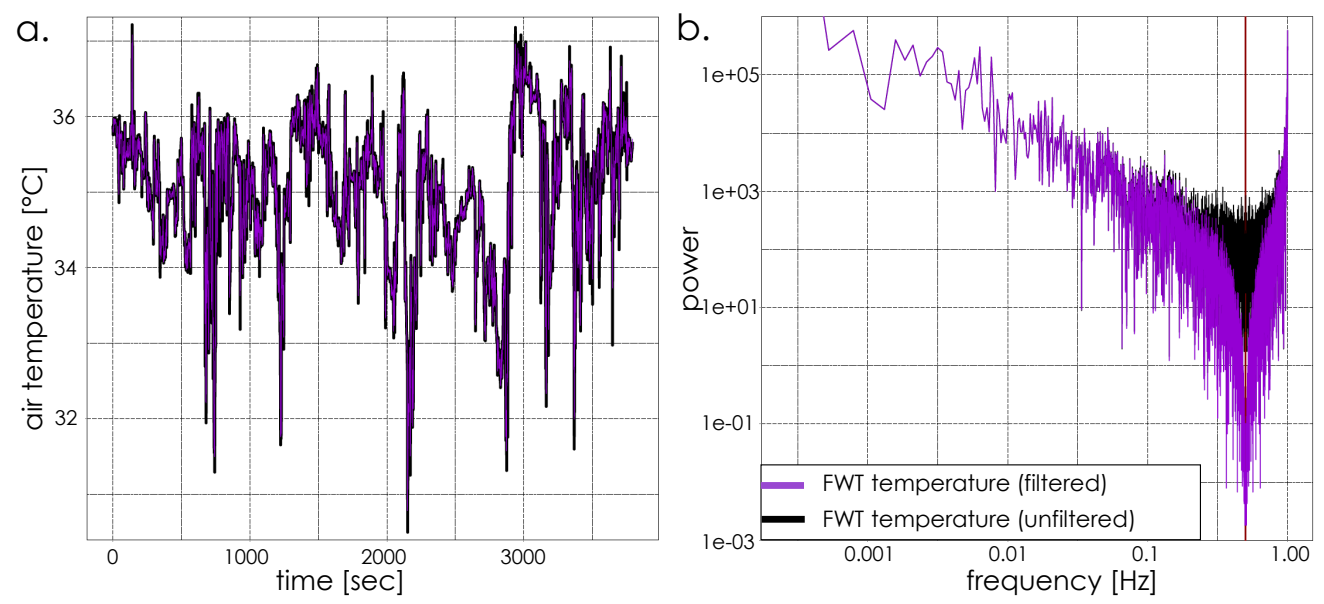

Figure 5: Time-detrended $1 \mathrm{~m} \mathrm{FWT}$ air temperature measurements (filtered and unfiltered) in the time and frequency domain. The time series was recorded on September 15, 2014, between 18:33 MST and 19:36 MST. (a) shows the time series, before and after the moving average has been applied. (b) displays these time series in the frequency domain. The red line indicates the Nyquist frequency.

each correction result, we then computed four error measures between the corrected RTD time series and the FWT measurements, whereas the latter have been filtered using a moving average window size of $2 \mathrm{~s}$. In particular, we computed the mean absolute error $(M A E)$, the maximal absolute error $\left(A E_{\max }\right)$, the root mean squared error (RMSE) and the index of agreement $d$ as described by Willmott [41, 42. The index of agreement is a dimensionless and easily interpretable value that indicates the accurateness of a prediction when compared to an observation. An index of agreement of $d=1$ denotes perfect prediction of the observed values by a model, while $d=0$ means disagreement [42]. The best combination of values should minimize $M A E, A E_{\max }$, and $R M S E$, while $d$ should be maximized.

To optimize across all data sets, we averaged each error measure over all data sets per parameter configuration, so that per parameter configuration and measurement height we yield four individual values for $M A E, A E_{\max }, R M S E$, and $d$. While the optimal parameter configuration should maximize $d$, the other er- 
ror measures $\left(R M S E, M A E\right.$, and $\left.A E_{\max }\right)$ should be minimized. Therefore, we computed an aggregate attribute by multiplying the error measures as follows:

$$
\Delta_{a g g r}=(1-d) \cdot R M S E \cdot M A E \cdot A E_{\max }
$$

The resulting table, consisting of the parameter configurations and their corresponding $\Delta_{a g g r}$, is now sorted according to $\Delta_{a g g r}$, and the first entry in the sorted table is assumed to be the best possible parameter configuration. Conducting this analysis separately for the two different measurement heights yields similar optimal correction parameters (Table 2). While the optimal moving average window size and the optimal choice for $\tau$ in Equation 5 are equal for both $1 m$ and $2 m$ air temperatures, the linear shift varies slightly. However, since our goal is the development of a rather "generic" correction scheme that is applicable to all settings given by our specific sensor setup and measurement campaign, we determined the correction parameters that work best for both heights. Thus, we first average corresponding error measures over both measurement heights, before we compute an overall $\Delta_{a g g r}$ for each applied parameter configuration.

\begin{tabular}{|l|l|l|l|l|l|l|l|l|}
\hline $\begin{array}{l}\text { Measurement } \\
\text { height }\end{array}$ & $\begin{array}{l}\text { Moving } \\
\text { average } \\
\text { window } \\
\text { size }\end{array}$ & $\begin{array}{l}\text { Choice for } \\
\boldsymbol{\tau} \text { in Eq. 5 }\end{array}$ & Time shift & Average d & $\begin{array}{l}\text { Average } \\
\text { RMSE }\end{array}$ & $\begin{array}{l}\text { Average } \\
\text { MAE }\end{array}$ & $\begin{array}{l}\text { Average } \\
\boldsymbol{A} E_{\text {max }}\end{array}$ & $\Delta_{\text {aggr }}$ \\
\hline $\begin{array}{l}1 \mathrm{~m} \\
\text { (regarded } \\
\text { separately) }\end{array}$ & 23 & 46.21 & 18 & 0.76 & 0.6333 & 0.4976 & 2.8029 & 0.212 \\
\hline $\begin{array}{l}2 \mathrm{~m} \\
\text { (regarded } \\
\text { separately) }\end{array}$ & 23 & 46.21 & 15 & 0.7891 & 0.4662 & 0.3748 & 2.171 & 0.08 \\
\hline $\begin{array}{l}1 \mathrm{~m} \text { and 2 } \mathrm{m} \\
\text { (regarded } \\
\text { together) }\end{array}$ & 23 & 46.21 & 16 & 0.7748 & 0.5505 & 0.4374 & 2.5041 & 0.1358 \\
\hline
\end{tabular}

Table 2: Optimal parameters and corresponding error measures for different measurement heights.

The results of the parameter optimization experiment are shown in Fig. 6 The upper part of Fig. 6 illustrates the development of the individual error measures according to the applied parameter configurations, which are depicted in the lower part of this Figure. It can be observed that the aggregated error $\Delta_{a g g r}$ is minimized for a unique combination of moving average window size, $\tau$ in Equation 5 , and amount of linear shift, which yields the parameter choice for 
the final method.

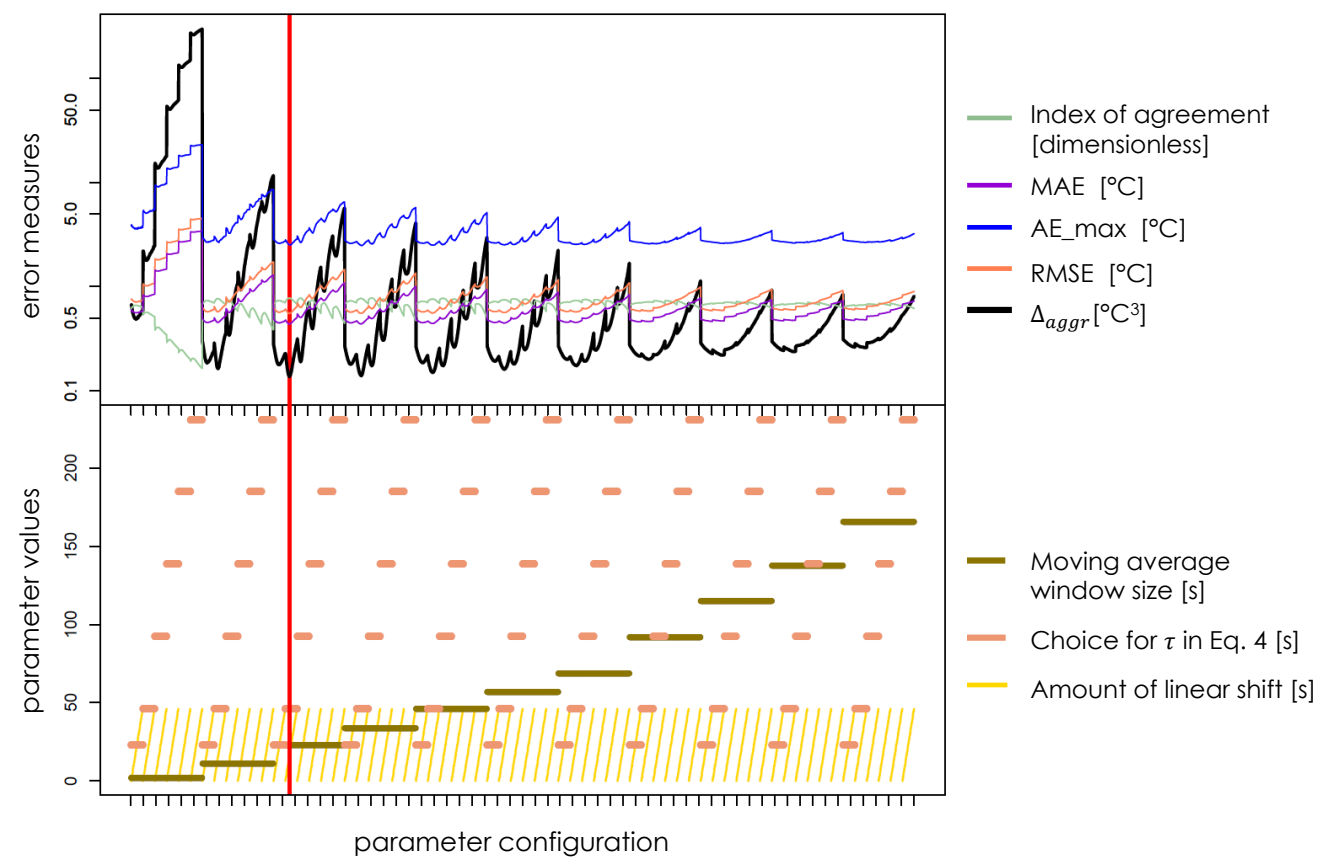

Figure 6: Upper image: Error measures for the parameter optimization experiment, averaged over all available measurement heights and data sets. The black line corresponds to the aggregated error, according to which we determined the optimal parameter choice. The results correspond to the parameter configurations shown on the lower image: All possible combinations of varying values for the three to-be-optimized parameters have been examined. The red line indicates the best result in terms of $\Delta_{a g g r}$.

\subsubsection{Final correction procedure}

The final method follows six steps (similar to [9, 14, 15]):

(i) Application of a two-sided unweighted moving average filter with a total window size of $0.5 \cdot \tau_{63, \text { mov }}=23$ to the raw, but time-detrended RTD data

(ii) Setup of the correction filter resulting from Equation 5 using $\tau_{63, \text { mov }}=46.21 \mathrm{~s}$, starting at $t=0$.

(iii) Fast Fourier Transform of both Equation 5 (yielding $H(f)$ ) and the filtered RTD data (yielding $G(f)$ ) 
(iv) Division of $G(f)$ by $H(f)$ to retrieve the true temperature spectrum

(v) Inverse Fourier transform of the true temperature spectrum, yielding the corrected RTD data without shift

(vi) Linear time shift of the corrected RTD data by $0.7 \cdot \tau_{63, \text { mov }} \approx 16 \mathrm{~s}$ backwards in time

For steps (i) and (vi) the input parameter needs to be an integer, therefore $\tau_{63, \text { mov }}$ was rounded to the closest integer. The algorithm was implemented using R 3.1.1 [43].

\section{Results and discussion}

\subsection{Sensor lag correction}

To verify our results, the corrected RTD temperature time series were compared to the respective time-detrended and filtered FWT time series sampled at the same height. The FWT measurements were used as a ground-truth because of their small time constant.

Figure 7 shows the verification results for 42 test cases consisting of $1 \mathrm{~m}$ and $2 \mathrm{~m}$ air temperature data for all 21 runs. The lower section of Figure 7 shows the improvement of the index of agreement $\Delta d$ between corrected HC2S3 Pt100 RTD time series and the ground-truth $d_{C O R R, F W T}$ and the uncorrected HC2S3 Pt100 RTD time series and the ground-truth $d_{U N C O R R, F W T}$, which is computed using $\Delta d=d_{C O R R, F W T}-d_{U N C O R R, F W T}$. Thus, positive values for $\Delta d$ indicate improvement by correction, while negative values mean that the correction procedure worsens the results. In nearly all cases, $d_{C O R R, F W T}$ exceeds $d_{U N C O R R, F W T}$ by at least 0.09 , thus indicating an improvement.

However, in two cases (February 05, 2015, 07:12 MST, $1 \mathrm{~m}$ and $2 \mathrm{~m}$ height, Fig. 7. bottom), the correction procedure lowered $\Delta d$ by 0.006 on average ${ }_{415}$ (Fig. 8b). This is also reflected in the values for the improvement of the $M A E$ through correction $\left(\triangle M A E=M A E_{C O R R, F W T}-M A E_{U N C O R R, F W T}\right)$, which are only negative for these two cases, adding up to $-0.03{ }^{\circ} \mathrm{C}$ for the $1 \mathrm{~m}$ time series and $-0.0007{ }^{\circ} \mathrm{C}$ for the $2 m$ time series. Although this difference is below 


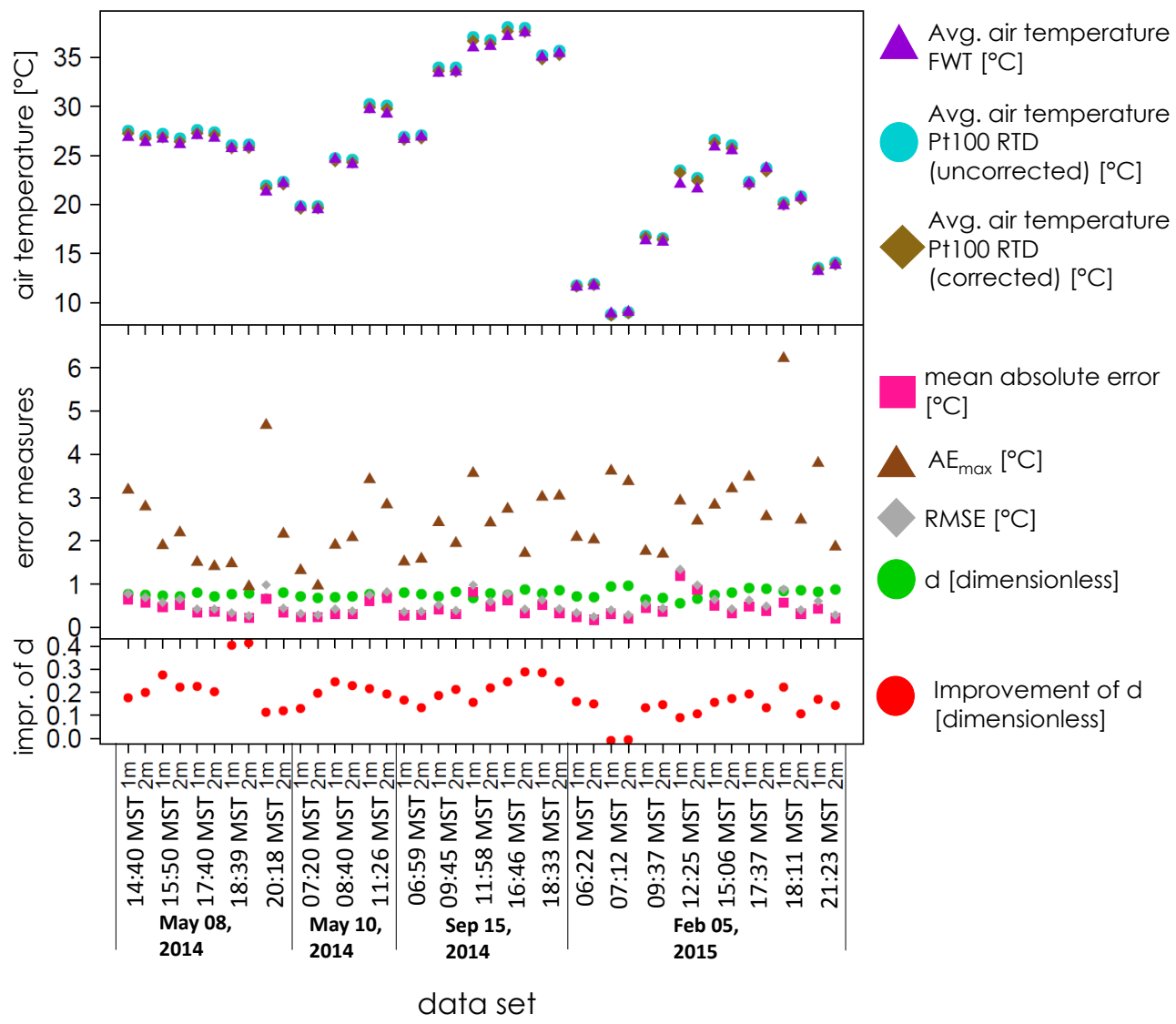

Figure 7: Data sets, their summaries and error analysis. Top: Average air temperatures per data set for each time series (filtered FWT, uncorrected HC2S3 Pt100 RTD measurements, and corrected HC2S3 Pt100 RTD measurements). All time series were time-detrended prior to correction. Center: Error between filtered FWT measurements ("ground-truth") and corrected HC2S3 Pt100 RTD measurements. Bottom: The improvement of the index of agreement $\Delta d$, which is determined by subtracting $d_{U N C O R R, F W T}$ from $d_{C O R R, F W T}$. 

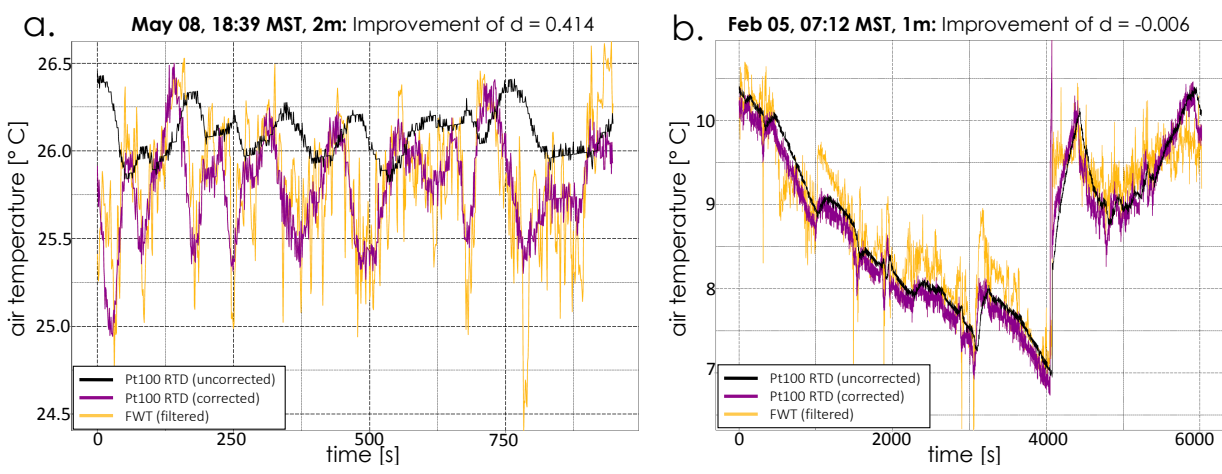

Figure 8: (a) Best and (b) worst correction result from a set of 42 test cases in terms of the improvement of $d$. The best and worst cases are determined by the difference of the index of agreement between measured and uncorrected data and d between measured and corrected data $\left(d_{C O R R, F W T}-d_{U N C O R R, F W T}\right)$. All time series were time-detrended prior to correction.

the accuracy of both the FTW and the HC2S3 Pt100 RTD sensor, it still indicates that the results become worse through correction. Further investigation of this issue revealed that a rapid and extreme air temperature increase logged at around second 4080 of this transect causes the corrected time series to "overshoot" the FWT time series (Fig. 8b). Replacing the affected time interval in both the $1 m$ and $2 m$ time series (seconds 4051 - 4076) with the corresponding values of the uncorrected HC3S2 Pt100 RTD time series results in positive value for $\Delta d$ for both the $1 m(\Delta d=0.004)$ and $2 m(\Delta d=0.004)$ case. $\Delta M A E$ for $2 m$ became positive as well $\left(\triangle M A E=0.008{ }^{\circ} \mathrm{C}\right)$, but it stayed negative for the $1 m$ case $\left(\triangle M A E=-0.02{ }^{\circ} \mathrm{C}\right)$.

The RMSE between ground-truth and RTD measurements ranges between $0.25{ }^{\circ} \mathrm{C}$ and $1.35{ }^{\circ} \mathrm{C}$, while staying below $1{ }^{\circ} \mathrm{C}$ for all cases except for the time series recorded at $1 m$ height on February 05, 2015, 12:25 MST. The same holds for the mean absolute error, which ranges between $0.18^{\circ} \mathrm{C}$ and $1.19^{\circ} \mathrm{C} . d$ is also lowest for the time series recorded at $1 m$ height on February 05, 2015, 12:25 MST, indicating an agreement of 0.56 between corrected RTD measurements 435 and ground-truth. Although these error measures do not imply a good result 
for this particular time series, the agreement between ground-truth and HC2S3 Pt100 RTD is still improved by the correction. On February 05, 18:11 MST, the corrected $1 \mathrm{~m}$ air temperatures show the highest deviation $\left(6.21{ }^{\circ} \mathrm{C}\right)$ between the corrected RTD temperature and the thermocouple readings in terms of the maximal absolute error (Fig. 7) center plot). RMSE and MAE stay below $1{ }^{\circ} \mathrm{C}$, with $d$ adding up to 0.84 for this data set. The high $A E_{\max }$ value is thus caused by fast fluctuations in the FWT temperature time series, which cannot be reconstructed due to the difference between the time constants of the RTDs and the FWTs, respectively.

The improvement of agreement can also be observed on the scatterplots shown in Figure 9, where the corrected HC2S3 Pt100 RTD time series align better with the 1:1 slope line, which would represent a perfect match to the FWT time series. This is also reflected in the overall RMSE, which is lower between FWT time series and corrected HC2S3 Pt100 RTD data. In general, the corrected HC2S3 Pt100 RTD measurements show larger local amplitudes, and the local maxima and minima are time-shifted to resemble the FWT time series (Figure $8 \mathrm{a}$ ). The average air temperature is altered only marginally by correction (Fig. 7, top), although the values measured by the FWT sensor are slightly lower than the corrected and uncorrected HC2S3 Pt100 RTD measurements.

455 In general, the algorithm is robust, even though we kept the time constant the same for all computations. This is an approximation, since the time constant is known to increase with decreasing ventilation, which occurs during decreasing platform velocities (e.g., Downs et al. [39], who determined the time constant for a HC2S3 Pt100 RTD for different air speeds). For the majority of time series available in our sample data set, the sensor platform stopped for smaller time intervals, which should theoretically lead to an increased $\tau_{63}$. Despite this inhomogeneous velocity distribution, the correction procedure leads to reliable results.

To further test the robustness of the correction procedure, we checked our 465 data set for systematic differences with respect to certain transect run categories. The results are shown in Figure 10. We distinguished between the measurement 

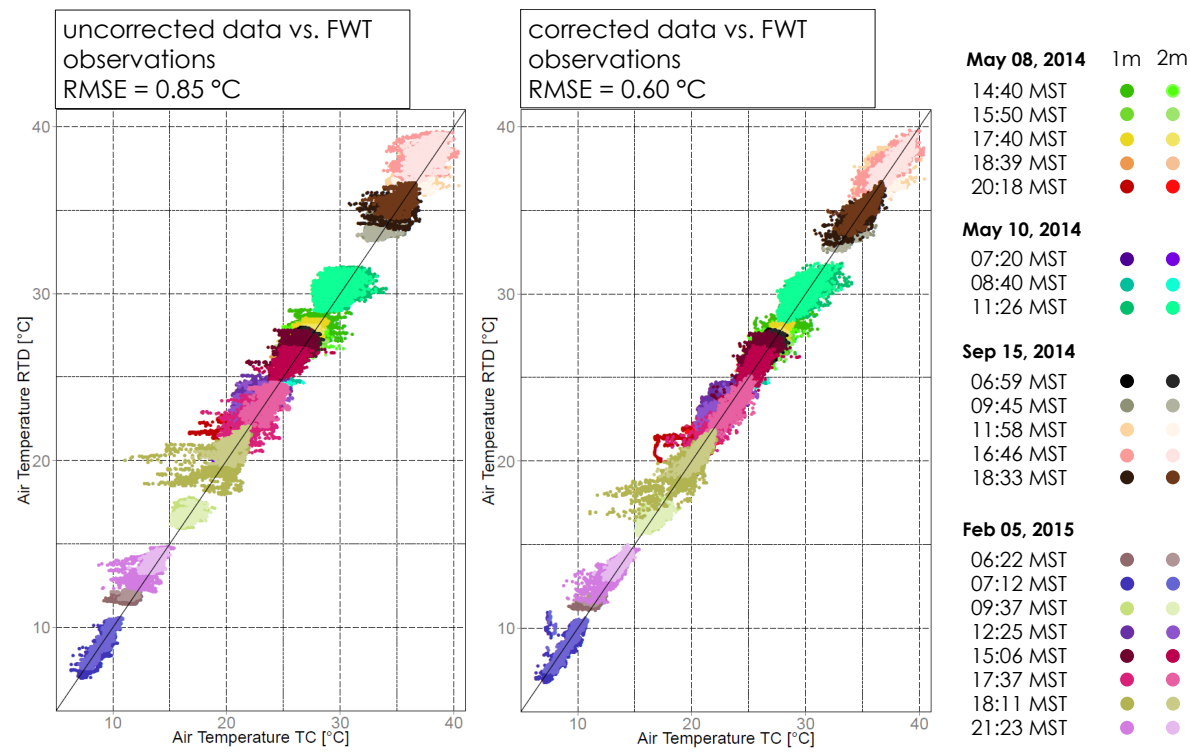

Figure 9: Correction results. The scatter plots display the alignment of the time-detrended and filtered FWT observations to the (a) uncorrected (but time-detrended) and (b) corrected RTD observations. The 1:1 slope lines shown on both scatterplots indicate perfect alignment. Different colors correspond to different time series, corresponding to Figure 2

days and the run kinds, i.e. between "tree runs" and "activity runs". A qualitative investigation of this plot shows that the performance of the correction procedure does not systematically diverge between these run categories.

\subsection{Limitations and further evaluation}

There are limitations to the generalizability of the correction algorithm. Although we achieved stable results for 42 time series representing measurements at two heights, different times of day, different seasons, and during different platform speeds, we only quantitatively validated the approach for one kind of sensor setup.

Furthermore, the FWT readings we used as ground-truth in this study do not represent the true temperature of the traversed environments because their response time is affected by the thermocouple time constant. However, with a time constant $\tau_{63}$ of approximately $0.6 \mathrm{sec}$ in still air, the FWT readings 


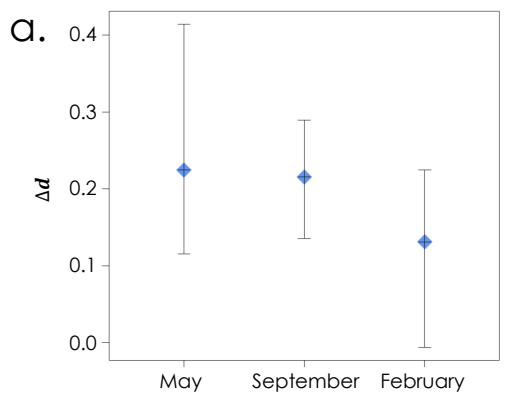

b.
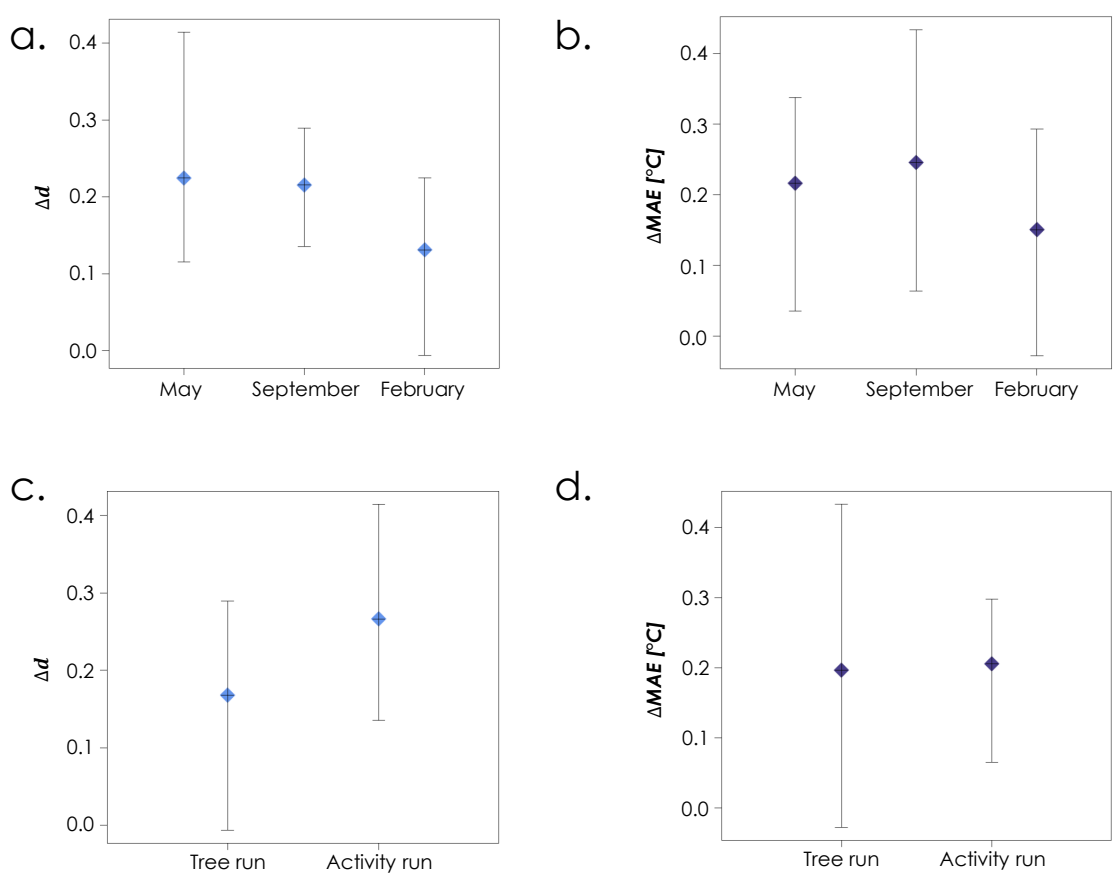

d.

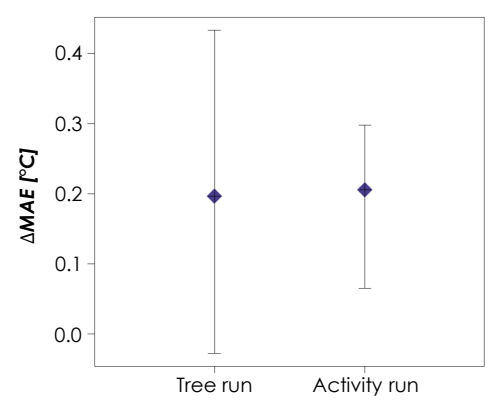

Figure 10: Average, minimum, and maximum values for $\Delta d$ and $\triangle M A E$ according to the different measurement days and run kinds. There are no systematic differences in the performance of the correction procedure with respect to the regarded run categories.

480

theoretically represent the surrounding microclimate with a fairly high spatial resolution, finer than that represented by this microenvironment.

For further evaluation, but without quantitative validation, we also tested the correction procedure for a time series sampled by another air temperature sensor: the Campbell Scientific HMP45C combined temperature and relative humidity probe. The time series was recorded on June 29, 2011, 11:11 MST, and was time-detrended as described in Section 2.4. During this transect run, the average speed of the sensor platform was $3.49 \mathrm{~m} / \mathrm{s}$ (averaged over all instances with a speed $>0 \mathrm{~m} / \mathrm{s}$, which was the case for $54.09 \%$ of all samples).

The HMP45C includes a platinum-type RTD with a resistance of $1000 \Omega$ (Pt1000 RTD), and an accuracy of $0.2{ }^{\circ} \mathrm{C}$ at $20^{\circ} \mathrm{C}$ 44. We experimentally determined $\tau_{63}$ for the HMP45C Pt1000 RTD using the approach described in 
Section 2.3, although we additionally conducted experiments to measure the time the cooled sensor needed to adapt to surrounding air temperatures. Postprocessing revealed a time constant of $128.15 \mathrm{~s}$ for wind speeds $>2.45 \mathrm{~m} / \mathrm{s}$. Based on these values, the correction procedure for the HMP45C yields a parameter setup with a moving average window size of $0.5 \cdot \tau_{63, \text { mov }} \approx 64 \mathrm{~s}$, a $\tau$ of $\tau_{63, \text { mov }}=128.15$ in Eq. 5, and a linear time shift by $0.7 \cdot \tau_{63, \text { mov }} \approx 90 \mathrm{~s}$. We lack a ground-truth for a quantitative validation and therefore only qualitatively analyzed the resulting time series. We observed that the local maximum and minimum air temperatures are amplified, which is one of the goals of the correction procedure.

From Table 3, uncorrected "slow" sensor observations, such as the HC2S3 Pt100 RTD or HMP45C Pt1000 RTD are not able to capture microclimate variability at the typical built environment spatial scales which are on the order of $10 \mathrm{~m}$. This is true even at relatively low platform velocities (or wind speeds) of $1 \mathrm{~m} / \mathrm{s}$. A "slow" sensor mounted on a near-stationary platform under "calm" wind conditions of roughly $0.1 \mathrm{~m} / \mathrm{s}$ can sample the $10 \mathrm{~m}$ scale microclimate, but this defeats the intent of a mobile and spatially distributed observation strategy. However, fine-wire thermocouples, or other sensors with a factory rated response time $\tau_{63}$ faster than $1 \mathrm{~Hz}$, can adequately sample microclimate variations at $10 \mathrm{~m}$ spatial scales even for platform velocities approaching typical urban vehicle traffic velocities of approximately $10 \mathrm{~m} / \mathrm{s}$.

As demonstrated in Section 3.1, the correction procedure described in this paper can help to approximate observations with a high spatial resolution (as provided by the FWT), even though the original data were recorded with a slower sensor (in this case the HC2S3 Pt100 RTD). An argument for a simple and optimized method for this correction were presented, and the optimal correction parameters were laid out in the previous Sections. It has to be noted, however, that this approximation can only succeed, if the slower sensor captured a signal 520 from the microclimate patch it traversed. 


\begin{tabular}{|l|l|l|l|l|l|l|}
\hline \multirow{2}{*}{$v[\mathrm{~m} / \mathrm{s}]$} & \multicolumn{5}{|l|}{$r^{*}:$ resolvable microclimate scale [m], $r^{*}=v \tau$} \\
\cline { 2 - 7 } & $\begin{array}{l}\text { Campbell Scientific FW3 } \\
\text { Thermocouples }\end{array}$ & \multicolumn{2}{l|}{$\begin{array}{l}\text { Rotronic HC2S3 } \\
\text { (Pt100 RTD) ** }\end{array}$} & \multicolumn{2}{l|}{$\begin{array}{l}\text { Campbell Scientific } \\
\text { HMP45C (Pt1000 RTD) *** }\end{array}$} \\
\cline { 2 - 7 } & $\tau_{63}=0.6 s$ & $\tau_{95}=1.8 s$ & $\tau_{63}=46.21 s$ & $\tau_{95}=138.63 s$ & $\tau_{63}=128.15 s$ & $\tau_{95}=384.44 s$ \\
\hline $\mathbf{0 . 1}$ & 0.06 & 0.18 & $\mathbf{4 . 6 2}$ & $\mathbf{1 3 . 8 6}$ & $\mathbf{1 2 . 8 2}$ & $\mathbf{3 8 . 4 4}$ \\
\hline $\mathbf{1}$ & 0.6 & 1.8 & $\mathbf{4 6 . 2 1}$ & $\mathbf{1 3 8 . 6 3}$ & $\mathbf{1 2 8 . 1 5}$ & $\mathbf{3 8 4 . 4 4}$ \\
\hline $\mathbf{5}$ & 3.0 & 9.0 & 231.05 & 693.15 & 640.75 & 1922.2 \\
\hline $\mathbf{1 0}$ & 6.0 & 18.0 & 462.10 & 1386.30 & 1281.50 & 3844.40 \\
\hline
\end{tabular}

* $\quad$ typical $\tau_{63}$ for this sensor (not experimentally determined)

** $\quad \tau_{63}$ experimentally determined using airspeeds greater than $3.2 \mathrm{~m} / \mathrm{s}$

*** $\quad \tau_{63}$ experimentally determined using airspeeds greater than $2.45 \mathrm{~m} / \mathrm{s}$

Bold: $\quad$ because $v$ is lower than the sensor's rated airspeed, $\tau$ and therefore also $r^{*}$ is underestimated

Table 3: Comparison of the resolvable microclimate scale at three different movement speeds, given by the time constants of different sensors.

\section{Conclusion}

In this study, we experimentally optimized a set of three parameters used in a procedure to correct air temperatures recorded with "slow" sensors for sensor inertia: Moving average window size, transfer function setup, and linear time shift. The correction procedure was mainly based on the algorithm described by Achberger and Bärring (1999) 9]. The linear time shift was added to the procedure as a final step in order to balance the effect of the transfer function on the intensification of local air temperature maxima and minima. The correction was carried out with a set of parameter configurations on time series measured with a HC2S3 Pt100 RTD. The optimal setting was determined by evaluating the error between the corrected time series and "ground-truth" FWT observations, taken simultaneously and at the same location. 
Although the time constant was assumed to be constant during all platform speeds, the optimized algorithm delivered robust results for nearly all of the investigated test cases. Thus, the corrections enhanced nearly all time series measured with slow sensors in terms of their alignment with a ground-truth. However, the correction procedure only works if the slower sensor recorded a signal representing a microscale land use patch. This capability is limited by the time constant of a sensor.

Although we covered different times of day, different seasons, and different measurement heights in our study, we only quantified results for one particular sensor setup. Therefore, further research is necessary to validate the suggested approach for other measurement settings, including other sensors.

We showed that measurements from slow sensors can be corrected to more closely resemble the measurements of faster sensors, and to approximate the effective spatial resolution of faster sensors, but some error is introduced. The performance of a sensor in terms of spatial resolution is an important consideration when observing the microclimate in an urban area or an otherwise spatially complex terrain.

\section{Acknowledgements}

This work was supported in part by the NSF Grant SES-0951366, Decision Center for a Desert City II: Urban Climate Adaptation, NSF EaSM Program EF-1049251, the NSF LTER Program CAP LTER 3 BCS-1026865, the Salt River Project grant to ASU, Alan and Sandra Ruffalo, and the Power Ranch Homeowners Association. Any opinions, findings, and conclusions or recommendations expressed in this material are those of the author(s) and do not necessarily reflect those of the National Science Foundation.

\section{References}

[1] B. G. Heusinkveld, G. J. Steeneveld, L. W. A. van Hove, C. M. J. Jacobs, A. A. M. Holtslag, Spatial variability of the Rotterdam urban heat island 
as influenced by urban land use, Journal of Geophysical Research: Atmospheres 119 (2) (2014) 677-692. doi:10.1002/2012JD019399.

URL http://dx.doi.org/10.1002/2012JD019399

n [2] M. Sofer, O. Potchter, The urban heat island of a city in an arid zone: the case of Eilat, Israel, Theoretical and Applied Climatology 85 (1-2) (2006) 81-88. doi:10.1007/s00704-005-0181-9.

URL http://dx.doi .org/10.1007/s00704-005-0181-9

[3] D. J. Murphy, M. H. Hall, C. A. S. Hall, G. M. Heisler, S. V. Stehman, C. Anselmi-Molina, The relationship between land cover and the urban heat island in northeastern Puerto Rico, International Journal of Climatology 31 (8) (2011) 1222-1239. doi:10.1002/joc.2145.

URL http://dx.doi.org/10.1002/joc.2145

口 [4] C.-Y. Sun, A. J. Brazel, W. T. Chow, B. C. Hedquist, L. Prashad, Desert

a heat island study in winter by mobile transect and remote sensing tech-

575 niques, Theoretical and Applied Climatology 98 (3-4) (2009) 323-335. doi:10.1007/s00704-009-0120-2.

URL http://dx.doi.org/10.1007/s00704-009-0120-2

[5] W. T. Chow, R. L. Pope, C. A. Martin, A. J. Brazel, Observing and mod-

n eling the nocturnal park cool island of an arid city: horizontal and vertical impacts, Theoretical and Applied Climatology 103 (1-2) (2011) 197-211. doi:10.1007/s00704-010-0293-8.

URL http://dx.doi.org/10.1007/s00704-010-0293-8

a [6] L. B. Stabler, C. A. Martin, A. J. Brazel, Microclimates in a desert city were related to land use and vegetation index, 585 Urban Forestry \& Urban Greening 3 (34) (2005) 137 - 147. doi:http://dx.doi.org/10.1016/j.ufug.2004.11.001

1 URL http://www.sciencedirect.com/science/article/pii/ S1618866704000329 
q [7] A. J. Brazel, D. M. Johnson, Land use effects on temperature and humidity in the Salt River Valley, Arizona, Urban Forestry \& Urban Greening 15 (2) (1980) 54-61. doi:10.2307/40024074.

URL http://www.jstor.org/stable/40024074

[8] J. K. Vanos, J. S. Warland, T. J. Gillespie, G. A. Slater, R. D. Brown, N. A. Kenny, Human energy budget modeling in urban parks in Toronto and applications to emergency heat stress preparedness, Journal of Ap-

1. plied Meteorology and Climatology 51 (9) (2012) 1639-1653. doi:10.1175/ JAMC-D-11-0245.1. URL http://dx.doi.org/10.1175/JAMC-D-11-0245.1

q [9] C. Achberger, L. Bärring, Correction of surface air temperature mea600

0 ogy 9899 (0) (1999) 227 - 238. doi:http://dx.doi.org/10.1016/ S0168-1923(99) 00099-4.

a URL http://www.sciencedirect.com/science/article/pii/ S0168192399000994

[10] T. Foken, Angewandte Meteorologie: Mikrometeorologische Methoden, Springer, Berlin/Heidelberg, 2006.

[11] J.-C. Mayer, K. Hens, U. Rummel, F. X. Meixner, T. Fo口 ken, Moving measurement platforms - specific challenges and corrections, Meteorologische Zeitschrift 18 (5) (2009) 477-488.

610 doi:doi:10.1127/0941-2948/2009/0401.

1. URL http://www.ingentaconnect.com/content/schweiz/mz/2009/ $00000018 / 00000005 /$ art00001

[12] R. G. Harrison, Natural ventilation effects on temperatures within Stevenson screens, Quarterly Journal of the Royal Meteorological Society 136 (646) (2010) 253-259. doi:10.1002/qj .537.

URL http://dx.doi.org/10.1002/qj.537 
[13] R. G. Harrison, Lag-time effects on a naturally ventilated large thermometer screen, Quarterly Journal of the Royal Meteorological Society 137 (655) (2011) 402-408. doi:10.1002/qj.745.

URL http://dx.doi.org/10.1002/qj.745

[14] J. McCarthy, A method for correcting airborne temperature data for sensor

1 response time, Journal of Applied Meteorology 12 (1) (1973) 211-214. doi: 10.1175/1520-0450(1973)012<0211:AMFCAT>2.0.C0;2. URL http://dx.doi .org/10.1175/1520-0450(1973)012<0211:AMFCAT> 2.0.CO;2

[15] G. W. Inverarity, Correcting airborne temperature data for lags introduced by instruments with two-time-constant responses, Journal of Atmospheric and Oceanic Technology 17 (2) (2000) 176-184. doi:10.1175/ 1520-0426(2000) 017<0176: CATDFL >2.0.CO;2. URL http://dx .doi .org/10.1175/1520-0426(2000)017<0176:CATDFL> 2.0.CO;2

[16] A. Mahesh, P. von Walden, S. G. Warren, Radiosonde temperature meaa surements in strong inversions: correction for thermal lag based on an experiment at the south pole, Journal of Atmospheric and Oceanic Technology 14 (1) (1997) 45-53. doi:10.1175/1520-0426(1997)014<0045: RTMISI $>2.0 . \mathrm{CO} ; 2$.

1 URL http://dx.doi.org/10.1175/1520-0426(1997)014<0045:RTMISI> $2.0 . \mathrm{CO} ; 2$

[17] S. Foster, P. Chan, Improving the wind and temperature measurements of an airborne meteorological measuring system, Journal of Zhejiang University SCIENCE A 13 (10) (2012) 723-746. doi:10.1631/jzus.A1100245. URL http://dx.doi.org/10.1631/jzus.A1100245

[18] A. Rodi, P. Spyers-Duran, Analysis of time response of airborne temperature sensors, Journal of Applied Meteorology 11 (3) (1972) 554-556. doi:10.1175/1520-0450(1972)011<0554:AOTROA>2.0.C0;2 

2.0. CO;2

[19] C. Jacobi, A. Scherf, A. Siemer, R. Roth, On the influence of sen-

URL http://dx.doi.org/10.1175/1520-0450(1972)011<0554:AOTROA>

- Sor inertia on the estimation of turbulent fluxes from aircraft measurements, Boundary-Layer Meteorology 76 (1-2) (1995) 97-108. doi:10.1007/ BF00710892.

URL http://dx.doi.org/10.1007/BF00710892

[20] L. M. Miloshevich, A. Paukkunen, H. Vömel, S. J. Oltmans, Development and validation of a time-lag correction for Vaisala radiosonde humidity measurements, Journal of Atmospheric and Oceanic Technology 21 (9) (2004) 1305-1327. doi:10.1175/1520-0426(2004)021<1305:DAVOAT>2.0.C0;2. URL http://dx.doi.org/10.1175/1520-0426(2004)021<1305:DAVOAT> $2.0 . \mathrm{CO} ; 2$

[21] J. Hübner, J. Olesch, H. Falke, F. X. Meixner, T. Foken, A horizontal mobile measuring system for atmospheric quantities, Atmospheric Measurement Techniques Discussions 7 (5) (2014) 4551-4588. doi:10.5194/ amtd-7-4551-2014.

URL http://www . atmos-meas-tech-discuss .net/7/4551/2014/

[22] I. D. Stewart, A systematic review and scientific critique of methodology in modern urban heat island literature, International Journal of Climatology 31 (2) (2011) 200-217. doi:10.1002/joc.2141.

URL http://dx.doi.org/10.1002/joc.2141

[23] United States Census Bureau, Incorporated places and minor civil divisions a datasets: Subcounty resident population estimates: April 1, 2010 to july 670 1, 2014 (Arizona) last accessed: 18/08/2015 (2015).

a URL http://www.census.gov/popest/data/cities/totals/2014/ files/SUB-EST2014_4.csv

[24] United States Census Bureau, State \& County QuickFacts, Gilbert (town), 
Arizona, last accessed: 19/08/2015 (2015).

URL http://quickfacts . census .gov/qfd/states/04/0427400.html

[25] World Meteorological Organization, World weather information service: Phoenix, Arizona, United States of America, Online, last accessed: 09/03/2014 (2014).

URL http://worldweather . wmo . int/en/city .html?cityId=806

[26] W. T. Chow, D. Brennan, A. J. Brazel, Urban heat island research in Phoenix, Arizona: Theoretical contributions and policy applications, Bulletin of the American Meteorological Society 93 (4) (2012) 517-530. doi:10.1175/BAMS-D-11-00011.1. URL http://dx.doi.org/10.1175/BAMS-D-11-00011.1

[27] J. D. Fast, J. C. Torcolini, R. Redman, Pseudovertical temperature profiles 1 and the urban heat island measured by a temperature datalogger network in Phoenix, Arizona, Journal of Applied Meteorology 44 (1) (2005) 3-13. doi:10.1175/JAM-2176.1. URL http://dx.doi.org/10.1175/JAM-2176.1

[28] A. Brazel, H. Fernando, J. Hunt, N. Selover, B. Hedquist, E. Pardyjak, Evening transition observations in Phoenix, Arizona, Journal of Applied Meteorology 44 (1) (2005) 99-112. doi:10.1175/JAM-2180.1.

URL http://dx.doi.org/10.1175/JAM-2180.1

[29] G. D. Jenerette, S. L. Harlan, W. L. Stefanov, C. A. Martin, Ecosystem services and urban heat riskscape moderation: water, green spaces, and social inequality in Phoenix, USA, Ecological Applications 21 (7) (2011) 2637-2651. doi:10.1890/10-1493.1. URL http://dx.doi.org/10.1890/10-1493.1

[30] J. Declet-Barreto, A. J. Brazel, C. A. Martin, W. T. L. Chow, S. L. Harlan, 700 Creating the park cool island in an inner-city neighborhood: heat mitigation strategy for Phoenix, AZ, Urban Ecosystems 16 (3) (2013) 617-635. 
doi: $10.1007 / \mathrm{s} 11252-012-0278-8$,

URL http://dx.doi .org/10.1007/s11252-012-0278-8

[31] Campbell Scientific, HC2S3 temperature and rh sensor brochure, Online, last accessed: 08/11/2014 (2014).

URL http://s.campbellsci.com/documents/us/product-brochures/

b_hc2s3.pdf

[32] Campbell Scientific, FW05, FW1, and FW3 Type E fine wire thermocouples brochure, Online, last accessed: 08/11/2014 (2012).

URL http://s.campbellsci.com/documents/us/product-brochures/

b_fw05-fw3.pdf

[33] Campbell Scientific, CR1000 measurement and control system: Operators manual, Online, last accessed: 08/11/2014 (2013).

URL http://s . campbellsci.com/documents/us/manuals/cr1000.pdf

715 [34] Omega, Unsheathed fine gage microtemp thermocouples J, K, T, E, R \& S, Online, last accessed: 08/11/2014 (2014).

URL http://www .omega.com/pptst/IRCO_CHAL_P13R_P10R.html

[35] K. Blennow, P. Persson, Modelling local-scale frost variations using mobile temperature measurements with a GIS, Agricultural and Forest Meteorology 89 (1) (1998) 59 - 71. doi:10.1016/S0168-1923(97)00057-9. S0168192397000579

[36] I. Eliasson, M. K. Svensson, Spatial air temperature variations and urban land use a statistical approach, Meteorological Applications 10 (2) (2003) 135-149. doi:10.1017/S1350482703002056.

URL http://dx.doi.org/10.1017/S1350482703002056

[37] E. Erell, T. Williamson, Intra-urban differences in canopy layer air temperature at a mid-latitude city, International Journal of Climatology 27 (9) 
(2007) 1243-1255. doi:10.1002/joc.1469.

[38] MesoWest / University of Utah, MesoWest data, Online, last accessed: 08/14/2014 (2014).

URL http://mesowest .utah.edu/index.html

[n] 39$]$ M. J. Downs, D. H. Ferriss, R. E. Ward, Improving the accuracy of the temperature measurement of gases by correction for the response delays in the thermal sensors, Measurement Science and Technology 1 (8) (1990) 717.

URL http://stacks. iop.org/0957-0233/1/i=8/a=008

[40] A. Zeileis, G. Grothendieck, J. A. Ryan, F. Andrews, S3 infrastructure for regular and irregular time series (z's ordered observations), last accessed: $11 / 05 / 2014$ (2014).

URL http://cran.r-project.org/web/packages/zoo/index.html

[41] C. J. Willmott, Some comments on the evaluation of model performance, Bulletin of the American Meteorological Society 63 (11) (1982) 1309-1313. doi:10.1002/joc.2141.

URL http://dx.doi.org/10.1002/joc.2141

[42] C. J. Willmott, On the validation of models, Physical Geography 2 (2) (1981) 184-194. doi:10.1080/02723646.1981.10642213

II URL http://www.tandfonline.com/doi/abs/10.1080/02723646.1981. 10642213

[43] R Core Team, R: A language and environment for statistical computing, $\mathrm{R}$ Foundation for Statistical Computing, Vienna, Austria (2014).

URL http://www.R-project .org/

[44] Campbell Scientific, HMP45C temperature and relative humidity probe brochure, Online, last accessed: 05/03/2014 (2011). 
URL https://s.campbellsci.com/documents/us/product-brochures/

b_hmp45c.pdf 